\title{
A NUMERICAL METHOD FOR SOLVING QUADRATIC INTEGER PROGRAMMING PROBLEM
}

\author{
V.M. Tat'yankin ${ }^{1}$, A.V. Shitselov ${ }^{1}$ \\ ${ }^{1}$ Yugra State University, Khanty-Mansiysk, Russian Federation \\ E-mails: bambar@bk.ru, anatoliy.shitselov@gmail.com
}

\begin{abstract}
We propose a new numerical method for solving quadratic integer programming problem. The algorithm is based on a special representation of a minimizer of the corresponding objective functional. The problem can be reduced to a special box-constrained integer least squares problem. The advantage of the proposed algorithm is a good computational performance (approximately $O(n \cdot \ln (n))$ operations) shown in numerical experiments, where the number of unknowns $n$ can be up to $10^{8}$. The computational complexity of the algorithm is confirmed experimentally by a large number of numerical experiments. The algorithm consists of 3 steps. At the average, a solution is found at the second step in 83,6 \% cases, while the third step gives solution in the remaining cases. The algorithm is realized with the use of the Python programming language. The results of numerical experiments can be found at the service GitHubGist. The elaborated software system was used to solve the problem on formation of the optimal order for education institutions in regions of the Russian Federation.
\end{abstract}

Keywords: nonlinear programming; integer programming; numerical method; optimization.

\section{Introduction}

Recently, nonlinear integer optimization is of particular interest due to its practical importance. Consider the model problem in the following form:

$$
\left\{\begin{array}{l}
\sum_{i=1}^{n}\left(\frac{P_{i}-X_{i}}{Z_{i}}\right)^{2} \longrightarrow \min , \\
\sum_{i=1}^{n} X_{i} \leq \min (S, A),
\end{array}\right.
$$

where all parameters are integers. Problem (1) arises in the problem on formation of the optimal order for education institutions in a region (see [1]), which can be reduced to the simpler problem of the form

$$
\left\{\begin{array}{l}
\sum_{i=1}^{n}\left(\frac{\lambda_{i}}{Z_{i}}\right)^{2} \longrightarrow \min , \\
\sum_{i=1}^{n} \lambda_{i}=E,
\end{array}\right.
$$

where $E=\sum_{i=1}^{n} P_{i}-\min (S, A)$ and $Z_{i} \geq 1$ are nonnegative integers, $\lambda_{i}, 0 \leq \lambda_{i} \leq E(i=$ $1,2, \ldots, n)$, are unknown nonnegative integers.

The change of variables $\lambda_{n}=-\sum_{i=1}^{n-1} \lambda_{i}$ reduces the problem to a very special case of the box-constrained integer least squares problem (see [2-4] and the problem on the closest point search in lattices (see the survey $[5,6]$ ), as well as the closest vector problem). General problems of this type are NP-hard (see [7, 8]). However, at present, there exist rather effective methods for solving these problems (see [3, Ch. 8; 6, 9-11] and the bibliography 
therein). The method proposed below is very simple and actually exact, and allows to involve a large number of the variables. Numerical experiments show an almost linear dependence of the computation time on the number of variables, from $O(n)$ to $O(n \cdot \ln (n))$.

\section{Main Results}

First of all, we give some theoretical justification of the algorithm. Consider the minimizer of problem (2) in the form $\lambda_{i}^{*}=\left[\beta_{i} \cdot 0,5+0,5\right], \beta_{i}=\left(\frac{Z_{i}}{Z_{n+1}}\right)^{2}(i=1,2, \ldots, n)$, where the number $Z_{n+1} \in(0, \infty)$ is to be determined.

Lemma 1. If there exists $Z_{n+1} \in(0, \infty)$ such that

$$
E=\sum_{i=1}^{n}\left[\beta_{i} \cdot 0,5+0,5\right], \beta_{i}=\left(\frac{Z_{i}}{Z_{n+1}}\right)^{2}
$$

then the numbers

$$
\lambda_{i}^{*}=\left[\beta_{i} \cdot 0,5+0,5\right], \beta_{i}=\left(\frac{Z_{i}}{Z_{n+1}}\right)^{2},(i=1,2, \ldots, n)
$$

give the minimum of functional (2).

Proof. Represent $\lambda_{i}^{*}$ in the form

$$
\lambda_{i}^{*}=\beta_{i} \cdot 0,5+0,5-x_{i}, \beta_{i}=\left(\frac{Z_{i}}{Z_{n+1}}\right)^{2},(i=1,2, \ldots, n),
$$

where $x_{i} \in[0 ; 1)$. Show that

$$
\sum_{i=1}^{n}\left(\frac{\lambda_{i}^{*}+\mu_{i}}{Z_{i}}\right)^{2} \geq \sum_{i=1}^{n}\left(\frac{\lambda_{i}^{*}}{Z_{i}}\right)^{2}
$$

for all integers $\mu_{i}$ such that $\sum_{i=1}^{n} \mu_{i}=0$.

Taking into account (3), present expression (4) as

$$
\begin{gathered}
\sum_{i=1}^{n} \frac{2 \cdot \lambda_{i}^{*} \cdot \mu_{i}+\mu_{i}^{2}}{Z_{i}^{2}} \geq 0 \\
\sum_{i=1}^{n} \frac{\beta_{i} \cdot \mu_{i}+\mu_{i}-2 \cdot x_{i} \cdot \mu_{i}+\mu_{i}^{*}}{Z_{i}^{2}} \geq 0 \\
\sum_{i=1}^{n^{2}} \frac{\mu_{i}-2 \cdot x_{i} \cdot \mu_{i}+\mu_{i}^{2}}{Z_{i}^{2}}+\sum_{i=1}^{n} \frac{\mu_{i}}{Z_{n+1}^{2}} \geq 0 \\
\sum_{i=1}^{n} \frac{\mu_{i}-2 \cdot x_{i} \cdot \mu_{i}+\mu_{i}^{2}}{Z_{i}^{2}} \geq 0 .
\end{gathered}
$$

Since $\mu_{i}^{2} \geq \mu_{i}$ for all integers $\mu_{i}$, inequality (5) is valid for all $x_{i} \in[0 ; 1)$. Therefore, expression (4) is also valid. This completes the proof.

Consider the function

$$
F\left(Z_{n+1}\right)=\sum_{i=1}^{n}\left[\left(\frac{Z_{i}}{Z_{n+1}}\right)^{2} \cdot 0,5+0,5\right]
$$


which does not increase in the variable $Z_{n+1}$ and takes nonnegative integer values. Obviously, if $Z_{i}=Z_{j}(i, j=1 \ldots n)$, then the function $F\left(Z_{n+1}\right)$ has the jump equal to $n$ at the discontinuity point. Therefore, the function $F\left(Z_{n+1}\right)$ does not take all integer values. Consequently, depending on the variable $Z_{i}$, the range of the function $F\left(Z_{n+1}\right)$ cannot coincide with the set of natural numbers. At the discontinuity point, we have

$$
F\left(Z_{n+1} \pm 0\right)=c \mp d,
$$

where $c, d$ are nonnegative integers and $d>1$. Since the functions

$$
\left(\frac{Z_{i}}{Z_{n+1}}\right)^{2} \cdot 0,5+0,5, i=1,2, \ldots, n
$$

are continuous, then the function

$$
\left[\left(\frac{Z_{i}}{Z_{n+1}}\right)^{2} \cdot 0,5+0,5\right]
$$

is a nonincreasing piecewise constant function taking all natural values when the independent variable run over the nonnegative semi-axis. The sum of these functions is also a nonincreasing piecewise constant function, and takes all nonnegative integers whenever all discontinuity points of these functions are different. Otherwise, this statement is not true. If two discontinuity points coincide, then the module of the jump is not less than 2 at each of these discontinuity points. Let us consider quantity (7) to be equal to a nonnegative integer $k$. We find that the discontinuity points of functions (8) have the form

$$
Z_{n+1}=Z_{i} /(2 k-1)^{1 / 2},(k=1,2, \ldots, \infty) .
$$

Two discontinuity points coincide whenever there exist nonnegative integers $k$ and $m$ (for $i \neq j$ ) that not exceed $n$ and

$$
Z_{i} /(2 k-1)^{1 / 2}=Z_{j} /(2 m-1)^{1 / 2},(k=1,2, \ldots, \infty, m=1,2, \ldots, \infty) .
$$

These equalities hold for different pairs of numbers $Z_{i}$ and $Z_{j}$. Consider the segment $[a, b]$ such that $F(a)>E$ and $F(b)<E$. Function (6) is piecewise constant, and the segment $[a, b]$ has $q$ discontinuity points. Denote these discontinuity points by $Z_{n+1}^{l}, l=$ $1,2, \ldots, q$, and enumerate in increasing order with respect to the number $l$. Consider the following two possible cases.

1. There exists the number $l$ such that $F\left(Z_{n+1}\right)=E$ for all $Z_{n+l}$ in $\left(Z_{n+1}^{l-1}, Z_{n+1}^{l}\right)$. By Lemma 1 , the numbers $\lambda_{i}^{*}=\left[\left(\frac{Z_{i}}{Z_{n+1}}\right)^{2} \cdot 0,5+0,5\right]$ give a solution to problem $(2)$ for these numbers $Z_{n+1}$.

2. There exists the number $l$ such that $F\left(Z_{n+1}^{l}-0\right)>E$ and $F\left(Z_{n+1}^{l}+0\right)=F\left(Z_{n+1}^{l+1}-\right.$ $0)<E$. This situation takes place under condition (9). For convenience, assume that the functions defining the function $F$ are continuous from the left. Consider Case 2 and denote

$$
\begin{aligned}
& \lambda_{i}^{1}=\left[\left(\frac{Z_{i}}{Z_{n+1}^{l}}\right)^{2} \cdot 0,5+0,5\right], i=1,2, \ldots, n, \\
& \lambda_{i}^{2}=\left[\left(\frac{Z_{i}}{Z_{n+1}^{l+1}}\right)^{2} \cdot 0,5+0,5\right], i=1,2, \ldots, n .
\end{aligned}
$$


In this case, $E+a=\sum_{i=1}^{n} \lambda_{i}^{1}$ and $E-b=\sum_{i=1}^{n} \lambda_{i}^{2}$, where $a$ and $b$ are nonnegative integers. Note that for $m=a+b$ there exists the jump of the function $F$ at $Z_{n+1}^{l}(m=$ $\left.F\left(Z_{n+1}^{l}-0\right)-F\left(Z_{n+1}^{l}+0\right)\right)$, and, hence, $a, b<m$. Consider the problem

$$
\left\{\begin{array}{l}
\sum_{i=1}^{n}\left(\frac{\lambda_{i}^{1}-y_{i}}{Z_{i}}\right)^{2} \longrightarrow \min , \\
a=\sum_{i=1}^{n} y_{i},
\end{array}\right.
$$

where the numbers $y_{i}$ are nonnegative integers. Consider numbers (10) such that the corresponding functions $\lambda_{i}^{1}\left(Z_{n+1}\right)$ has the discontinuity point at $Z_{n+1}^{l}$. Assume that these numbers are $\lambda_{1}^{1}, \lambda_{2}^{1}, \ldots, \lambda_{m}^{1}$, else renumber these numbers. The remaining functions $\lambda_{t}^{1}\left(Z_{n+1}\right)$ are continuous at this point for $t \geq m+1$.

Lemma 2. In Case 2, the solution to problem (2) can be represented as $\lambda_{i}=\lambda_{i}^{1}-y_{i}$, if $y_{i}=0$ for $i=m+1, \ldots, n$ and $y_{i} \in\{0,1\}$ for $i=1, \ldots, m, a=\sum_{i=1}^{m} y_{i}$.

Therefore, problem (2) is reduced to the following problem having the less dimension:

$$
\left\{\begin{array}{l}
\sum_{i=1}^{m}\left(\frac{\lambda_{i}^{1}-y_{i}}{Z_{i}}\right)^{2} \longrightarrow \min , \\
a=\sum_{i=1}^{m} y_{i}
\end{array}\right.
$$

where the minimum is taken over the numbers $y_{i} \in\{0,1\}$.

Proof. Let us show that there exist numbers $y_{i} \in\{0,1\}(j=1,2, \ldots, m)$ such that

$$
\sum_{t=m+1}^{n}\left(\frac{\lambda_{t}^{1}}{Z_{t}}\right)^{2}+\sum_{j=1}^{m}\left(\frac{\lambda_{j}^{1}-y_{j}}{Z_{j}}\right)^{2} \leq \sum_{i=1}^{n}\left(\frac{\lambda_{i}^{1}+c_{i}}{Z_{i}}\right)^{2}
$$

for all integers $c_{i}$, if $-a=\sum_{i=1}^{n} c_{i}$. Transform (12) as follows:

$$
\sum_{t=m+1}^{n}\left(\frac{\lambda_{t}^{1}}{Z_{t}}\right)^{2}+\sum_{j=1}^{m}\left(\frac{\lambda_{j}^{1}}{Z_{j}}\right)^{i=1}+\sum_{j=1}^{m} \frac{\left(y_{j}\right)^{2}}{\left(Z_{j}\right)^{2}}-\frac{2 y_{j} \lambda_{j}^{1}}{\left(Z_{j}\right)^{2}} \leq \sum_{i=1}^{n}\left(\frac{\lambda_{i}^{1}}{Z_{i}}\right)^{2}+\sum_{i=1}^{n} \frac{\left(c_{i}\right)^{2}}{\left(Z_{i}\right)^{2}}+\frac{2 c_{i} \lambda_{i}^{1}}{\left(Z_{i}\right)^{2}}
$$

By construction,

$$
\begin{aligned}
& 2 \lambda_{j}^{1}=\left(\frac{Z_{j}}{Z_{n+1}^{l}}\right)^{2}+1, j=1,2, \ldots, m, \\
& 2 \lambda_{i}^{1}=\left(\frac{Z_{i}}{Z_{n+1}^{l}}\right)^{2}+1-2 \alpha_{i}, i=1,2, \ldots, n,
\end{aligned}
$$

where $\alpha_{i}$ is the fractional part of the quantity $\frac{1}{2}\left(\left(\frac{Z_{i}}{Z_{n+1}^{l}}\right)^{2}+1\right)$. Taking into account (14), rewrite (13) in the form

$$
\sum_{j=1}^{m} \frac{\left(y_{j}\right)^{2}}{\left(Z_{j}\right)^{2}}-\frac{y_{j}\left(\left(\frac{Z_{j}}{Z_{n+1}^{l}}\right)^{2}+1\right)}{\left(Z_{j}\right)^{2}} \leq \sum_{i=1}^{n} \frac{\left(c_{i}\right)^{2}}{\left(Z_{i}\right)^{2}}+\frac{c_{i}\left(\left(\frac{Z_{i}}{Z_{n+1}^{l}}\right)^{2}+1-2 \alpha_{i}\right)}{\left(Z_{i}\right)^{2}}
$$


which can be transformed as follows:

$$
\sum_{j=1}^{m} \frac{\left(y_{j}\right)^{2}-y_{j}}{\left(Z_{j}\right)^{2}}-\frac{\sum_{j=1}^{m} y_{j}}{\left(Z_{n+1}^{l}\right)^{2}} \leq \sum_{i=1}^{n} \frac{\left(c_{i}\right)^{2}+c_{i}\left(1-2 \alpha_{i}\right)}{\left(Z_{i}\right)^{2}}+\frac{\sum_{i=1}^{n} c_{i}}{\left(Z_{n+1}^{l}\right)^{2}} .
$$

Substitute $\sum_{j=1}^{m} y_{j}=a$ and $\sum_{i=1}^{n} c_{i}=-a$ in $(32)$ :

$$
\sum_{j=1}^{m} \frac{\left(y_{j}\right)^{2}-y_{j}}{\left(Z_{j}\right)^{2}} \leq \sum_{i=1}^{n} \frac{\left(c_{i}\right)^{2}+c_{i}\left(1-2 \alpha_{i}\right)}{\left(Z_{i}\right)^{2}}
$$

The function $\sum_{j=1}^{m} \frac{\left(y_{j}\right)^{2}-y_{j}}{\left(Z_{j}\right)^{2}}$ has a zero global minimum, which is achieved for $y_{j} \in\{0,1\}$ such that $a=\sum_{j=1}^{m} y_{j}$. These numbers $y_{j}$ exist, since $a<m$. Therefore, the left-hand side of (15) is removed, while the right-hand side is always nonnegative for all admissible numbers $c_{i}$.

Lemma 3. The minimum of functional (11) is equal to

$$
\sum_{i=1}^{m}\left(\frac{\lambda_{i}^{1}}{Z_{i}}\right)^{2}-\frac{a}{\left(Z_{n+1}^{l}\right)^{2}}
$$

and is achieved for every set of the numbers $y_{i} \in\{0,1\}$ such that $a=\sum_{i=1}^{m} y_{i}$.

Proof. For example, consider the following set of numbers: $y_{j}=1$ for $j=1,2, \ldots, a$ and $y_{j}=0$ for $j=a+1, \ldots, m$. Consider the objective functional (see (11))

$$
\sum_{j=1}^{a}\left(\left(\frac{\lambda_{j}^{1}}{Z_{j}}\right)^{2}-2\left(\frac{\lambda_{j}^{1} \cdot y_{j}}{Z_{j}^{2}}\right)+\left(\frac{y_{j}}{Z_{j}}\right)\right)^{2}+\sum_{t=j+1}^{m}\left(\frac{\lambda_{t}^{1}}{Z_{t}}\right)^{2} .
$$

Transform the expression above and arrive at the quantity

$$
\sum_{j=1}^{\alpha}\left(-2\left(\frac{\lambda_{j}^{1} \cdot y_{j}}{Z_{j}^{2}}\right)+\left(\frac{y_{j}}{Z_{j}}\right)^{2}\right)+\sum_{i=1}^{m}\left(\frac{\lambda_{i}^{1}}{Z_{i}}\right)^{2} .
$$

Substitute (10) in (16) and obtain

$$
\sum_{j=1}^{\alpha}\left(-2\left(\frac{\left(\left(\frac{Z_{j}}{Z_{n+1}^{l}}\right)^{2} \cdot 0,5+0,5\right) \cdot y_{j}}{Z_{j}^{2}}\right)+\left(\frac{y_{j}}{Z_{j}}\right)^{2}\right)+\sum_{i=1}^{m}\left(\frac{\lambda_{i}^{1}}{Z_{i}}\right)^{2}
$$

Transform (17) and obtain the expression

$$
\sum_{i=1}^{m}\left(\frac{\lambda_{i}^{1}}{Z_{i}}\right)^{2}-\frac{a}{\left(Z_{n+1}^{l}\right)^{2}}
$$

Obviously, this expression is independent of the numbers $y_{j}$, and, therefore, is the minimum of functional (11). 
The main result is as follows.

Theorem 1. There exists the number $l$ such that either $F\left(Z_{n+1}\right)=E$ for all $Z_{n+1}$ in $\left(Z_{n+1}^{l-1}, Z_{n+1}^{l}\right)$, or $F\left(Z_{n+1}^{l}-0\right)>E$ and $F\left(Z_{n+1}^{l}+0\right)=F\left(Z_{n+1}^{l+1}-0\right)<E$. In the first case, the numbers $\lambda_{i}^{1}=\left[\left(\frac{Z_{i}}{Z_{n+1}}\right)^{2} \cdot 0,5+0,5\right]$ give a solution to problem (2) for the numbers $Z_{n+1}$ in $\left(Z_{n+1}^{l-1}, Z_{n+1}^{l}\right)$. In the second case, suppose that $m$ is the jump of $F$ at $Z_{n+1}^{l}$ and $\lambda_{i}^{1}, i=1,2, \ldots, m$, are the functions having a discontinuity point at $Z_{n+1}^{l}$ (otherwise, we can renumber). Let $a=\sum_{i=1}^{n} \lambda_{i}^{1}-E$. Then the minimum of functional (2) is achieved at the numbers $\lambda_{i}=\lambda_{i}^{1}-y_{i}$, if $y_{i}=0$ for $i=m+1, \ldots, n, y_{i} \in\{0,1\}$ for $i=1, \ldots, m$, and $a=\sum_{i=1}^{m} y_{i}$.

\section{Description of Algorithm}

First of all, we find the segment containing the necessary discontinuity point $Z_{n+1}^{l}$.

Lemma 4. Suppose that $F\left(Z_{n+1}^{l}-0\right) \geq E$ and $F\left(Z_{n+1}^{l}+0\right) \leq E$, then

$$
Z_{n+1}^{\text {below }}=\sqrt{\frac{\sum_{i=1}^{n} Z_{i}^{2}}{2 E+n}} \leq Z_{n+1}^{l} \leq Z_{n+1}^{\text {above }}=\sqrt{\frac{\sum_{i=1}^{n} Z_{i}^{2}}{2 E-n}} .
$$

Proof. $F\left(Z_{n+1}^{l}-\varepsilon\right) \geq E$ for every $\varepsilon>0$. We have that

$$
E=\sum_{i=1}^{n}\left[\beta_{i} \cdot 0,5+0,5\right] \leq \sum_{i=1}^{n}\left(\beta_{i} \cdot 0,5+0,5\right) \beta_{i}=\left(\frac{Z_{i}}{Z_{n+1}^{l}-\varepsilon}\right)^{2} .
$$

Hence, we obtain that

$$
Z_{n+1}^{l}-\varepsilon \leq Z_{n+1}^{a b o v e}=\sqrt{\frac{\sum_{i=1}^{n} Z_{i}^{2}}{2 E-n}}
$$

On the other hand,

$$
E=\sum_{i=1}^{n}\left[\beta_{i} \cdot 0,5+0,5\right] \geq \sum_{i=1}^{n} \beta_{i} \cdot 0,5+0,5, \beta_{i}=\left(\frac{Z_{i}}{Z_{n+1}^{l}+\varepsilon}\right)^{2},
$$

and, therefore,

$$
Z_{n+1}^{\text {below }}=\sqrt{\frac{\sum_{i=1}^{n} Z_{i}^{2}}{2 E+n}} \leq Z_{n+1}^{l}+\varepsilon
$$

The number $\varepsilon>0$ is arbitrary. This completes the proof.

Describe main steps of the algorithm.

1. Determine the quantities

$$
a=\sqrt{\frac{\sum_{i=1}^{n} Z_{i}^{2}}{2 E-n}}, b=\sqrt{\frac{\sum_{i=1}^{n} Z_{i}^{2}}{2 E+n}} .
$$


If $F(a)=E$ or $F(b)=E$, then, for the known (by Lemma 1) solution, we have that $\lambda_{i}^{*}=\left[\left(\frac{Z_{i}}{a}\right)^{2} \cdot 0,5+0,5\right]$ or $\lambda_{i}^{*}=\left[\left(\frac{Z_{i}}{b}\right)^{2} \cdot 0,5+0,5\right]$. Otherwise, go to Step 2.

2. Use the algorithm of the dichotomy method [12]. There are two possible situations. First, we find $Z_{n+1}$ such that $F\left(Z_{n+1}\right)=E$. Then $\lambda_{i}^{*}=\left[\left(\frac{Z_{i}}{Z_{n+1}}\right)^{2} \cdot 0,5+0,5\right]$ is a solution to problem (2). Second, we find an interval $(a, b)$ containing only such discontinuity points of $F$ that $F(a+0)=E+\alpha$ or $F(b-0)=E-\beta$, where $\alpha, \beta>0$ are integers. Then go to Step 3.

3. Find the discontinuity point $Z_{n+1}^{l}$ of function (6) on the new interval $(a, b)$. We have that $F\left(Z_{n+1}^{l}\right)>E$. Calculate $\lambda_{i}^{1}=\left[\left(\frac{Z_{i}}{Z_{n+1}^{l}}\right)^{2} \cdot 0,5+0,5\right]$ and look for a solution to problem (2) in the form $\lambda_{i}^{*}=\left[\lambda_{1}^{1}-1, \ldots, \lambda_{\alpha}^{1}-1, \lambda_{\alpha+1}^{1}, \ldots, \lambda_{m}^{1}, \ldots, \lambda_{n}^{1}\right]$, where the functions $\lambda_{j}^{1}\left(Z_{n+1}^{l}\right), j=1, \ldots, m$ have a discontinuity point at $Z_{n+1}^{l}$, while the remaining functions $\lambda_{t}^{1}\left(Z_{n+1}^{l}\right), t \geq m+1$, are continuous at this point.

\section{Realization of Algorithm}

In order to realize the proposed algorithm, we use the language "Python" and the service GitHubGist. The service is an open remote control system to verify software and numerical experiments. The algorithm was applied to different sets of data (see Table 1).

Table 1

Numerical experiment scenarios

\begin{tabular}{|l|l|l|}
\hline № & Number of variables, $n$ & Number of experiments \\
\hline 1 & 10 & 500 \\
2 & 100 & 500 \\
3 & 1000 & 500 \\
4 & 10000 & 500 \\
5 & 100000 & 500 \\
6 & 1000000 & 500 \\
7 & 10000000 & 500 \\
8 & 100000000 & 500 \\
\hline
\end{tabular}

Analyzing the algorithm, we can note that a solution can be found at every step of the algorithm. Hence, we pay attention to the following two problems.

First, obtain the dependence of the computation time on the number of variables (see Figure). Second, obtain the probability to find a solution at every step of the algorithm (see Table 2).

The results of the numerical experiments and their realizations can be found at https://gist.github.com/pyro-bot/20fd75fb283d1241be372df1b3869539.

\section{Conclusion}

According to Figure, the dependence of the computation time on the number of variables is almost linear and is at most $O(n \cdot \ln (n))$. Also, note that a solution is determined at Step 2 in $83 \%$ cases, while Step 3 gives a solution in the remaining $17 \%$ cases. 


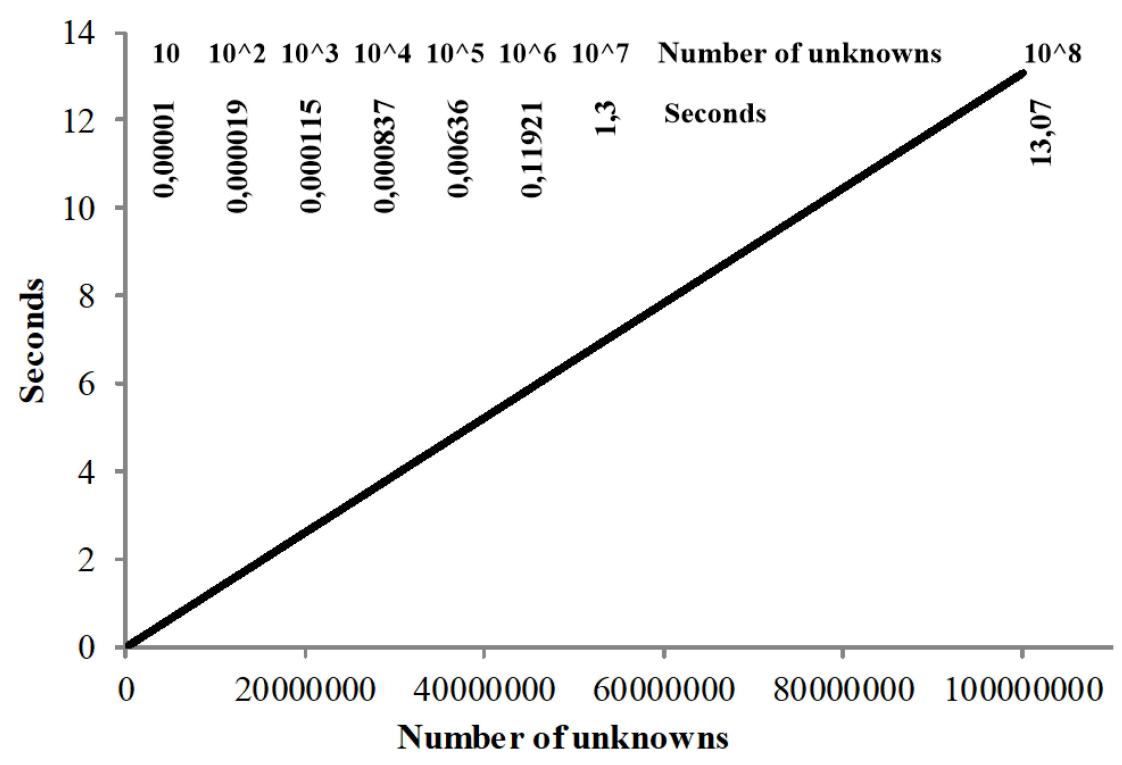

Computational complexity of the algorithm

Table 2

Probability to find a solution at every step of the algorithm

\begin{tabular}{|l|l|l|}
\hline $\begin{array}{l}\text { Number } \\
\text { unknowns }\end{array}$ & $\begin{array}{l}\text { Number of solutions } \\
\text { determined at Step 2 }\end{array}$ & $\begin{array}{l}\text { Number of solutions } \\
\text { determined at Step 3 }\end{array}$ \\
\hline $10^{1}$ & 3288 & 712 \\
$10^{2}$ & 2861 & 639 \\
$10^{3}$ & 2479 & 521 \\
$10^{4}$ & 2076 & 424 \\
$10^{5}$ & 1670 & 330 \\
$10^{6}$ & 1247 & 253 \\
$10^{7}$ & 846 & 154 \\
$10^{8}$ & 440 & 60 \\
Average probability & 0,836 & 0,164 \\
\hline
\end{tabular}

Acknowledgement. This work was supported by the science foundation of Yugra State University under grant no. 13-01-20/13.

\section{References}

1. Tat'yankin V.M. [Methods and Algorithms for Control of Staffing Processes in a Region]. PhD Thesis, Novosibirsk, 2017. (in Russian)

2. Buchheim C., De Santis M., Palagi L., Piacentini M. An Exact Algorithm for Nonconvex Quadratic Integer Minimization Using Ellipsoidal Relaxations. SIAM Journal on Optimization, 2013, vol. 23, no. 3, pp. 1867-1889. DOI: 10.1137/120878495

3. Buchheim C., Caprara A., Lodi A. An Effective Branch-and-Bound Algorithm for Convex Quadratic Integer Programming. Mathematical Programming, 2012, vol. 135, no. 1-2, pp. 369-395. DOI: 10.1007/s10107-011-0475-x 
4. Xiao Wen Chang, Qing Han. Solving Box-Constrained Integer Least Squares Problems. IEEE Transactions on Wireless Communications, 2008, vol. 7, no. 1, pp. 277-287. DOI: $10.1109 /$ TWC.2008.060497

5. Agrell E., Eriksson T., Vardy A., Zeger K. Closest Point Search in Lattices. IEEE Transactions on Information Theory, 2002, vol. 48, no. 8, pp. 2201-2214. DOI: $10.1109 /$ TIT.2002.800499

6. Duan Li, Xiaoling Sun. Nonlinear Integer Programming. N.Y., Springer Science and Business Media, 2006.

7. Van Emde Boas P. Another NP-Complete Partition Problem and the Complexity of Computing Short Vectors in a Lattice. Amsterdam, University of Amsterdam, 1981.

8. Axehill D. Integer Quadratic Programming for Control and Communication. PhD Thesis. Linköping, Institutionen för systemteknik, 2008.

9. Lee J., Leyffer S. Mixed Integer Nonlinear Programming. N.Y., Dordrecht, Heidelberg, London, Springer Science and Business Media, 2012. DOI: 10.1007/978-1-4614-1927-3

10. Hemmecke R., Köppe M., Lee J., Weismantel R. Nonlinear Integer Programming. 50 Years of Integer Programming 1958-2008. Berlin, Heidelberg, Springer, 2010, pp. 561-618. DOI: $10.1007 / 978-3-540-68279-0 \_15$

11. Borno M.A. Reduction in Solving Some Integer Least Squares Problems. Montreal, McGill University, 2011.

12. Mudrov A.E. Chislennye metody dlya PEVM na yazykah Beysik, Fortran i Paskal' [The Numerical Computer Solution with Use of Basic, Fortran, and Pascall. Tomsk, Rasko, 1991. (in Russian)

Received December 11, 2018

УДК 519.854.3

DOI: $10.14529 / \mathrm{mmp} 190311$

\title{
ЧИСЛЕННЫЙ МЕТОД РЕШЕНИЯ ЗАДАЧИ ЦЕЛОЧИСЛЕННОГО И КВАДРАТИЧНОГО ПРОГРАММИРОВАНИЯ ОПРЕДЕЛЕННОГО ВИДА
}

\author{
В.М. Татъянкин ${ }^{1}$, А.В. Шицелов ${ }^{1}$ \\ ${ }^{1}$ Югорский государственный университет, г. Ханты-Мансийск, \\ Российская Федерация
}

\begin{abstract}
Предлагается новый численный метод решения задачи целочисленного программирования квадратичного вида. Алгоритм основан на специальном представлении минимизатора соответствующего целевого функционала. Проблема может быть сведена к специальной задаче с наименьшими квадратами с ограничениями. Для разработанного метода был предложен алгоритм решения задачи целочисленного программирования квадратичного вида. Преимущество представленного алгоритма заключается в невысокой вычислительной сложности, в среднем, которая оценивается в $\mathrm{O}(\mathrm{nln}(\mathrm{n}))$. Данная вычислительная сложность подтверждена экспериментально. Эксперимент заключался в решении задачи при количестве неизвестных $10,10^{2}, \ldots, 10^{8}$. Каждое вычисление производилось 500 раз. Разработанный алгоритм состоит из 3 шагов. В среднем, в 83,6 \% случаях, решение находилось на 2 шаге, оставшиеся решения - на 3 шаге.
\end{abstract}


Численный эксперимент реализован на языке «Руthon» и размещен на сервисе GitHubGist. Прикладное значение разработанного алгоритма заключается в его использовании для решения задачи «Формирование оптимального регионального заказа на подготовку профессиональных кадров по учреждениям высшего и среднего образования в Российской Федерации».

Ключевые слова: нелинейное программирование; иелочисленное программирование; численный метод; оптимизация.

\section{Литература}

1. Татьянкин, В.М. Методы и алгоритмы для управления процессами кадрового обеспечения региона: дис. ... канд. техн. наук / В.М. Татьянкин. - Новосибирск, 2017.

2. Buchheim, C. An Exact Algorithm for Nonconvex Quadratic Integer Minimization Using Ellipsoidal Relaxations / C. Buchheim, M. De Santis, L. Palagi, M. Piacentini // SIAM Journal on Optimization. - 2013. - V. 23, № 3. - P. 1867-1889.

3. Buchheim, C. An Effective Branch-and-Bound Algorithm for Convex Quadratic Integer Programming / C. Buchheim, A. Caprara, A. Lodi // Mathematical Programming. - 2012. V. 135, № 1-2. - P. 369-395.

4. Xiao Wen Chang. Solving Box-Constrained Integer Least Squares Problems / Xiao Wen Chang, Qing Han // IEEE Transactions on Wireless Communications. - 2008. - V. 7, № 1. P. 277-287.

5. Agrell, E. Closest Point Search in Lattices / E. Agrell, T. Eriksson, A. Vardy, K. Zeger // IEEE Transactions on Information Theory. - 2002. - V. 48, № 8. - P. 2201-2214.

6. Duan Li. Nonlinear Integer Programming / Duan Li, Xiaoling Sun. - New York: Springer Science and Business Media, 2006.

7. Van Emde Boas, P. Another NP-Complete Partition Problem and the Complexity of Computing Short Vectors in a Lattice / P. van Emde Boas. - Amsterdam: University of Amsterdam. - 1981.

8. Axehill, D. Integer Quadratic Programming for Control and Communication. PhD Thesis / D. Axehill. - Linköping: Institutionen för systemteknik, 2008.

9. Lee, J. Mixed Integer Nonlinear Programming / J. Lee, S. Leyffer. - New York; Dordrecht; Heidelberg; London: Springer Science and Business Media, 2012.

10. Hemmecke, R. Nonlinear Integer Programming. Optimization and Control / R. Hemmecke, M. Köppe, J. Lee, R. Weismantel // 50 Years of Integer Programming 1958-2008. - Berlin; Heidelberg: Springer, 2010. - P. 561-618.

11. Borno, M.A. Reduction in Solving Some Integer Least Squares Problems / M.A. Borno. Montreal: McGill University. - 2011.

12. Мудров, А.Е. Численные методы для ПЭВМ на языках Бейсик, Фортран и Паскаль / А.Е. Мудров. - Томск: Раско, 1991.

Виталий Михайлович Татьянкин, кандидат технических наук, доцент, Югорский государственный университет (г. Ханты-Мансийск, Российская Федерация), bambar@bk.ru.

Анатолий Вячеславович Шицелов, преподаватель, Югорский государственный университет (г. Ханты-Мансийск, Российская Федерация), anatoliy.shitselov@gmail.com.

Поступила в редакиию 11 декабря 2018 г. 